45

\title{
Desafío Diagnóstico
}

\section{Arritmia extrasistólica con QRS ancho:}

\section{¿Ventricular o conducción aberrante?}

\author{
René Asenjo \\ Departamento Cardiovascular, Hospital Clínico Universidad de Chile \\ Departamento de Cardiología, Clínica Alemana de Santiago.
}

Presentamos trazados de un registro de Holter de 24hrs, solicitado por episodios de palpitaciones a un paciente de 65 años, con antecedente de hipertensión arterial. Las figuras muestran dos trazados de 3 derivaciones del Holter, de la cuales el canal 1 y 3 equivalen a un V3 y V5 y la derivación 2 a un V1. Se observa ritmo sinusal (RS) de base de aproximadamente 72/min, con PR normal y QRS angosto, con extrasístoles aislados de complejo angosto, y extrasístoles de complejo ancho aislados, en pares y una salva de 3 complejos.

¿De qué origen es esta arritmia extrasistólica?

En el trazado 1, hay dos extrasístoles de complejo angosto (señalados como $\mathrm{S}$ en la figura $\mathrm{B}$ ), los que son similares a los complejos en RS, pero en el primero el complejo QRS es de menor amplitud y exhibe discreto retardo terminal. Son precedidos de una onda $\mathrm{P}^{\prime}$ adelantada (cabeza de flecha), por lo que corresponden a extrasístoles auriculares, el primero de ellos conducido con discreta aberrancia.

El resto de los extrasístoles son de complejo ancho de 2 morfologías, asignadas como A y B. Ambos tienen configuración de bloqueo de rama derecha (BRD), ya que el QRS es predominantemente positivo en V1.

Con los elementos disponibles en estos trazados debemos definir si corresponden a extrasístoles supraventriculares (ESV) conducidos con aberrancia, o a extrasístoles ventriculares $(\mathrm{EV})$.

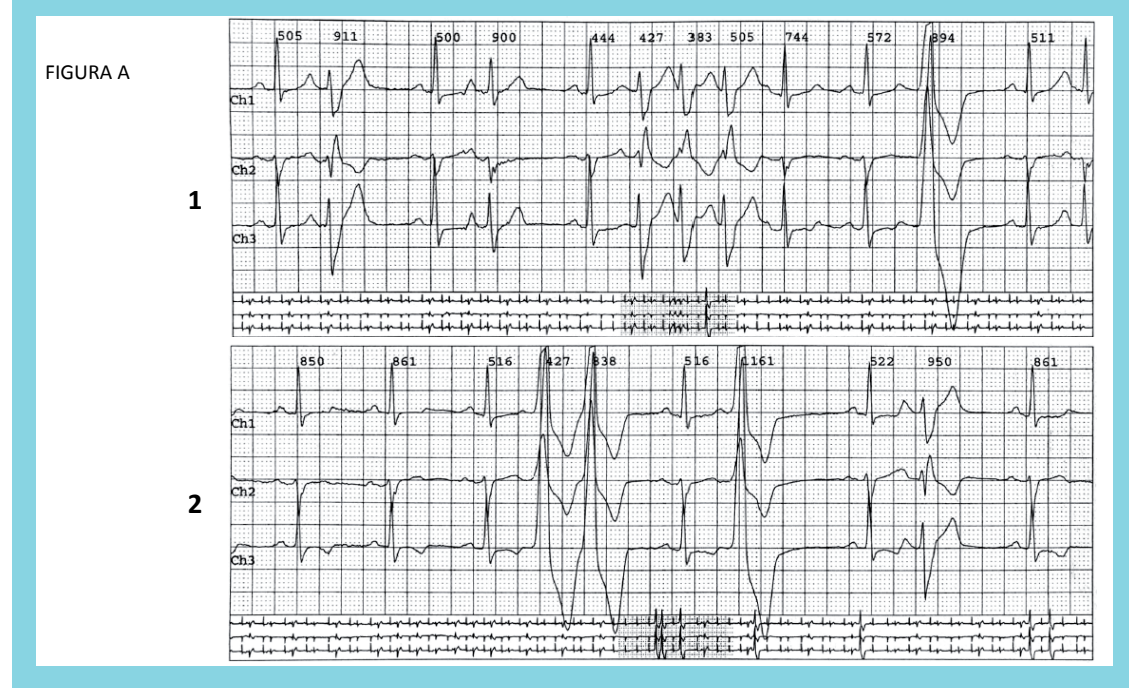

Correspondencia:

Dr. René Asenjo G.

rene.asenjog@gmail.com 


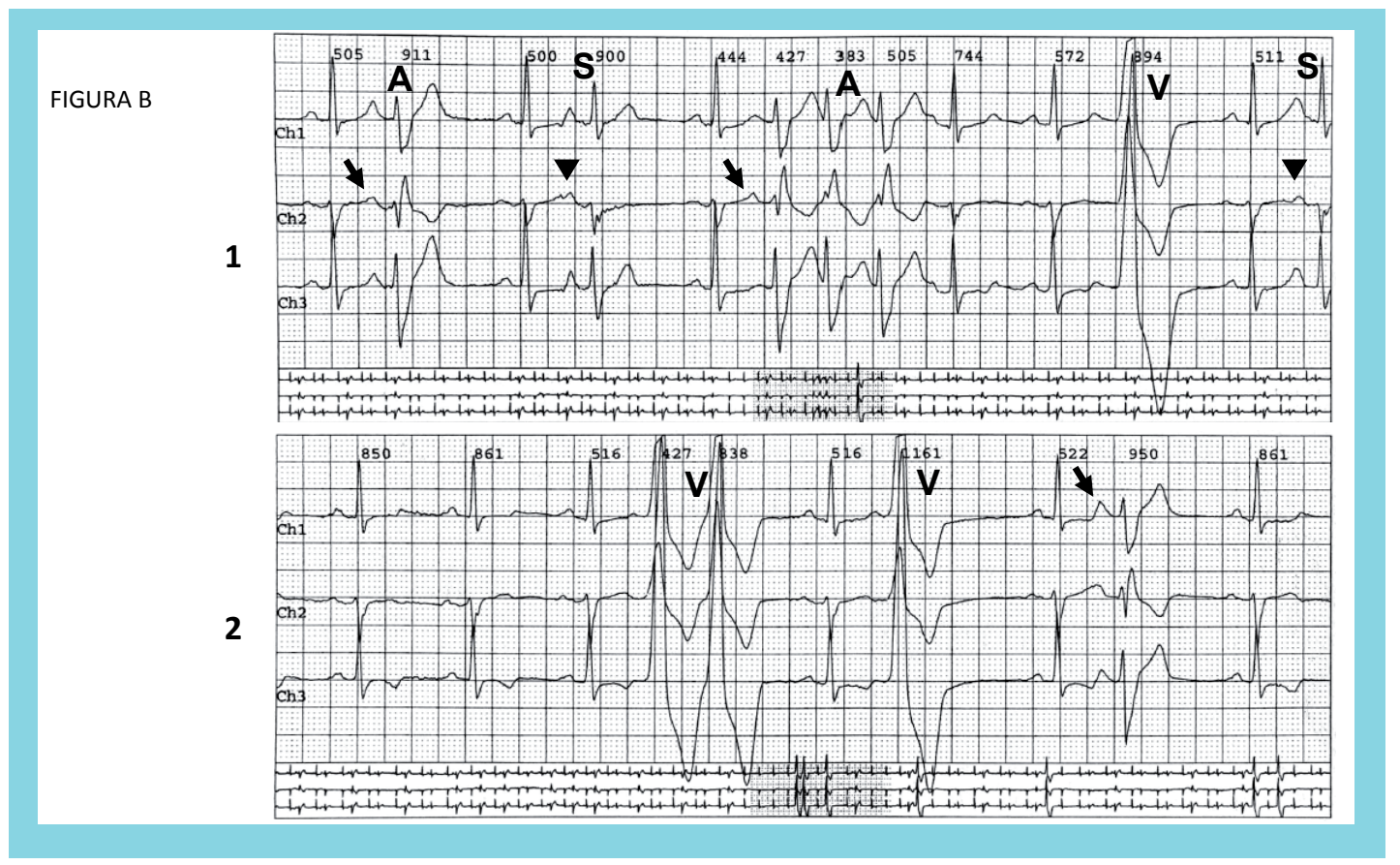

Existen tanto extrasístoles ventriculares, como extrasístoles supraventriculares conducidos con aberrancia

\section{1.- Características morfológicas de los complejos.}

En un Holter, sólo V1 es parte de las derivaciones validadas para diferenciar el origen de un complejo QRS ancho. Los extrasístoles de morfología A tienen un complejo rsR', con activación rápida de su primera porción y activación lenta de su parte final (la onda $\mathrm{S}$ es empastada y la onda R' ancha). Esta configuración es típica de un BRD y aberrancia de conducción. Se explica porque la activación ventricular de un estímulo SV ocurre a través del sistema de conducción de His-Purkinje, que tiene una velocidad de conducción mucho más rápida que la del miocardio ventricular. Por lo tanto, la activación inicial es rápida y el ensanchamiento del QRS ocurre fundamentalmente a expensas de su porción terminal. En un complejo de origen ventricular, en cambio, la activación inicial es lenta, por el mayor tiempo que demora su recorrido a través del miocardio ventricular hasta alcanzar el sistema de conducción normal.

Lo complejos de morfología $\mathrm{V}$, tienen una onda $\mathrm{R}$ de ascenso lento y son monofásicos en V1, característica de muy alta especificidad de un origen ventricular. Además, el único complejo de esta morfología del trazado 1 exhi- be una pausa compensadora completa, también indicativo de EV.

\section{2.- Onda $P^{\prime}$ previo a los complejos anchos}

La búsqueda de ondas $\mathrm{P}^{`}$ prematuras requiere observar cuidadosamente el segmento ST y onda T que preceden al complejo QRS ancho, y compararlos con aquellos complejos sinusales no interrumpidos por extrasístoles. Los complejos anchos de la morfología A son precedidos por una deformación de la repolarización ventricular del complejo sinusal previo, debido a ondas $\mathrm{P}^{`}$ prematuras (flechas), correspondientes a extrasístoles auriculares, las que no se observan en los complejos de morfología V.

\section{3.- Características del ciclo cardíaco}

Un tercer elemento de ayuda es la presencia de una pausa en el ciclo que precede al extrasístole de complejo ancho. Como la duración del potencial de acción cambia según la longitud del ciclo precedente, al haber una pausa se prolonga el período refractario. Si el estímulo SV siguiente es precoz, es probable que encuentre una de las ramas del sistema His-Purkinje en período refractario relativo o absoluto y se conduzca con aberrancia. Este bloqueo de rama funcional es más común en la rama derecha, ya que su período refractario es más largo que el 
14

de la rama izquierda. La aberrancia posterior a una pausa es conocida como fenómeno de Ashman y fue descrito como un elemento diferenciador de EV en pacientes con fibrilación auricular.

En este caso, el extrasístole auricular con aberrancia parcial, así como los extrasístoles de complejo ancho de la morfología A, ocurren luego de una pausa, lo que orienta a aberrancia. Luego de la salva de 3 complejos con conducción aberrante, el latido siguiente -que parece sinusal- es angosto, porque seguramente el ciclo corto previo $(383 \mathrm{~ms})$ ha acortado el período refractario de la rama derecha, permitiendo que se conduzca sin retardo. Así, en este Holter, los complejos prematuros anchos aislados y la salva de 3 complejos de la morfología A corresponden a extrasistolía auricular conducida con aberrancia, y los de morfología $\mathrm{V}$ a EV aislada y en pares.

\section{Referencias}

1. SANDLER IA, MARRIOTT HJ. The differential morphology of anomalous ventricular complexes of BBB-type in lead V1: ventricular ectopy versus aberration. Circulation 1965;31:551-6.
2.- MARRIOTT HJL, CONOVER MB. Aberrancy versus ectopy. En Marriott-Conover, Advanced Concepts in Arrhythmias, Third Edition. St. Louis, Missouri, USA: Mosby,Inc;1998. p.237-260. 